\title{
The presence of children in households was associated with dietary intake among Japanese married women: the POTATO study
}

\author{
Aki Saito $^{1,2}$, Mai Matsumoto ${ }^{3}$, Aiko Hyakutake ${ }^{4}$, Masafumi Saito ${ }^{5}$ and Naoko Okamoto ${ }^{6}$ \\ ${ }^{1}$ Department of Nutritional Epidemiology and Shokuiku, National Institutes of Biomedical Innovation, Health and Nutrition, Tokyo, Japan \\ ${ }^{2}$ Department of Nutrition and Food Science, Graduate School of Humanities and Sciences, Ochanomizu University, Tokyo, Japan \\ ${ }^{3}$ Department of Human Nutrition, Seitoku University, Chiba, Japan \\ ${ }^{4}$ Department of Nutrition, Faculty of Nutrition, Kobe Gakuin University, Hyogo, Japan \\ ${ }^{5}$ Department of Clinical Dietetics and Human Nutrition, Faculty of Pharmaceutical Sciences, Josai University, Saitama, Japan \\ ${ }^{6}$ Department of Health and Nutrition, Osaka Shoin Women's University, Osaka, Japan
}

(Received 8 December 2017 - Final revision received 26 February 2018 - Accepted 5 March 2018)

Journal of Nutritional Science (2018), vol. 7, e16, page 1 of 9

doi:10.1017/jns.2018.9

\section{Abstract}

A growing body of evidence from Western countries shows that the presence of children in households is associated with the dietary intake of adults, but little is known about this relationship in non-Western countries with different food cultures. Our aim was to examine whether dietary intake was different with respect to the presence of young children in the home among Japanese married women. Subjects were Japanese married women (aged 23-44 years) living with children aged less than 5 years $(n 73)$ and married women who did not have children $(n 85)$. Data regarding habitual dietary intake were obtained using a validated, self-administered diet history questionnaire. A cross-sectional comparison between women with young children and women without children was conducted using ANCOVA adjusted for potential confounding factors. Women with young children had a significantly greater intake of protein, carbohydrates, $\mathrm{Na}, \mathrm{Zn}$ and $\mathrm{Cu}$ than did women without children. Intake of cereals, pulses and sugar was significantly higher among mothers than among non-mothers. Intake of both alcoholic and non-alcoholic beverages was significantly higher among non-mothers than among mothers. Thus, the presence of young children at home might influence women's intake of macronutrients and some minerals, especially Na, and beverages among Japanese married women. Our findings suggest that effective dietary interventions among Japanese mothers with young children may differ from those of married women without children.

Key words: Women: Children: Mothers: Dietary intake: Japan

Dietary behaviour in the early stages of life could influence dietary intake later on in life ${ }^{(1-3)}$ and could even affect the future risk of non-communicable diseases ${ }^{(4)}$. Improving dietary habits of children is an important public health issue. Similarities in dietary intake among parents and their children have been observed in several studies ${ }^{(5,6)}$. A systematic review reported various similarities such as energy and macronutrient intake $^{(5)}$. A more recent US study observed the relationships between diet quality and energy intake of parents and those of their children ${ }^{(7)}$. Thus, children's diet is regarded as being influenced primarily by that of their parents ${ }^{(6)}$.

On the other hand, adults' lifestyle may also be affected by having children. The transition to parenthood can have a large impact on health and related behaviours such as increased $\mathrm{BMI}^{(8,9)}$ and decreased physical activity ${ }^{(10-12)}$. Several studies have compared dietary intake between parents and nonparents, and a significant difference in the intake of several nutrients and food items was observed ${ }^{(12-16)}$. For example,

Abbreviation: BDHQ, brief-type, self-administered diet history questionnaire.

* Corresponding author: Aki Saito, email saitoa@nibiohn.go.jp

(C) The Author(s) 2018. This is an Open Access article, distributed under the terms of the Creative Commons Attribution licence (http://creativecommons.org/licenses/by/4.0/), which permits unrestricted re-use, distribution, and reproduction in any medium, provided the original work is properly cited. 
US mothers reported greater intake of sugar-sweetened beverages, total energy and saturated fat than non-mothers ${ }^{(12)}$. In another US study, the presence of children in the household was associated with significantly higher total and saturated fat intake among adults ${ }^{(13)}$. A UK study showed that women who had children under the age of 16 years had higher vegetable intake and lower fruit intake than did women without children under the age of 16 years ${ }^{(14)}$. Finnish women who had children were shown to have a dietary intake closer to dietary guidelines, such as greater consumption of fruits and vegetables ${ }^{(15)}$, than did non-mothers. Moreover, a previous study in the USA reported that the presence of a young child was positively associated with fruit and vegetable consumption ${ }^{(16)}$. Additionally, some longitudinal studies have examined the change in dietary intake during the transition to parenthood ${ }^{(17-22)}$. Among these studies, some reported that dietary patterns of women starting a family had changed unfavourably ${ }^{(21,22)}$. For instance, a Canadian study showed that first-time mothers decreased their fruit intake ${ }^{(21)}$, while an Australian study reported that women starting a new family increased their energy intake and consumption of high-fat foods, sugar, fruit and cooked vegetables $^{(22)}$. There have been mixed results reported regarding the association between the presence of children in a household and the dietary intake of adults; however, despite a stronger association between dietary intake in children and their parents being observed in countries other than European countries and the $\mathrm{USA}^{(5)}$, we are unaware of any comparable research reported in Asian countries, including Japan, where the food culture is quite different from that of Western countries. Typically, the diet consumed by Japanese people is characterised by high intakes of rice, soyabean products, fish, seaweeds and green tea, as well as lower fat intake than that of Western countries ${ }^{(23,24)}$. To obtain reliable scientific evidence on the presence of children in a household and the dietary intake of adults, it will be necessary to accumulate studies of this kind conducted in various regions with different social and cultural backgrounds. Furthermore, there have been few reports on whether the presence of children influences overall nutrient intake, not only specific nutrients, in married women.

It has also been reported that mothers have stronger influences on their children's dietary intake than do fathers ${ }^{(7,25-27)}$, and maternal modelling of healthy food habits can influence children's diet quality ${ }^{(28)}$. Understanding the difference in dietary intake between women living with young children and those living without children will be important in proposing dietary strategies for the health of not only mothers, but also the next generation.

Here, we examined the influence of the presence of young children in the home on women's dietary intake. The objective of this study was to characterise the difference in dietary intake profiles of married women with children younger than 5 years old and married women without children, in Japan.

\section{Methods}

\section{Procedure}

This report describes a cross-sectional, self-administered questionnaire study (the POTATO study) conducted between June and December 2014 and between July and August 2015. Married women aged 23-44 years, with or without a preschool child or children younger than 5 years old, living in Japan, were recruited via an advertisement for volunteer collaborators (snowball sampling). A collaborator explained the survey's purpose and outline using a document distributed to a total of 353 married women who were asked to complete questionnaires about dietary habits and lifestyle. To compare the dietary intake of mothers of preschool children (younger than 5 years old) and women without children, inclusion criteria for subjects' age was set between 23 and 44 years, because the birth rate was highest for women between the ages of 30 and 34 years and dropped at 40 years in Japan ${ }^{(29)}$. A total of 241 women completed both questionnaires (response rate $=$ $68.3 \%$ ). This study was conducted according to the guidelines laid down in the Declaration of Helsinki, and all procedures involving human subjects were approved by the Ethics Committee of Seitoku University (no. H25U017). Written informed consent was obtained from all the participants.

\section{Study population}

The present analyses were limited to those women who either lived with husbands only or with husbands and children aged younger than 5 years ( $n$ 232). We excluded the following respondents: those who were receiving nutritional counselling (n 2), those who were pregnant or lactating (n 63), those who reported energy intake less than half the energy requirement for the lowest physical-activity category according to the Japanese Dietary Reference Intakes $2015^{(30)}$, and those reporting equal to or more than 1.5 times the energy requirement for the highest physical activity category $(n 3)$. There were no missing data on the variables analysed.

According to the number of children reported in the lifestyle questionnaire, the subjects were categorised into two groups women with children younger than 5 years old and women without children. Those who had children aged over 5 years were excluded ( $n$ 8). The final sample thus consisted of 158 Japanese married women aged 25-44 years categorised into the following two groups: subjects with young children ( $n$ $85)$ and without children (n 73) (Fig. 1).

\section{Dietary assessment}

Dietary habits during the preceding month were assessed using a previously validated brief-type, self-administered diet history questionnaire (BDHQ) ${ }^{(31,32)}$. The BDHQ is a structured questionnaire that includes questions about intake frequencies of selected foods commonly consumed in Japan, general dietary behaviours and usual cooking methods. The daily intake estimates for foods (fifty-eight items in total), energy and selected nutrients were calculated using an ad hoc computer algorithm developed for the BDHQ, which was based on the Standard Tables of Food Composition in Japan ${ }^{(33)}$. Validity of the BDHQ and its structure, as well as the methods used to calculate dietary intake, have been detailed as referenced above. In a previous study of ninety-two women aged 31-69 years, the median Pearson's correlation coefficients of nutrient intake 


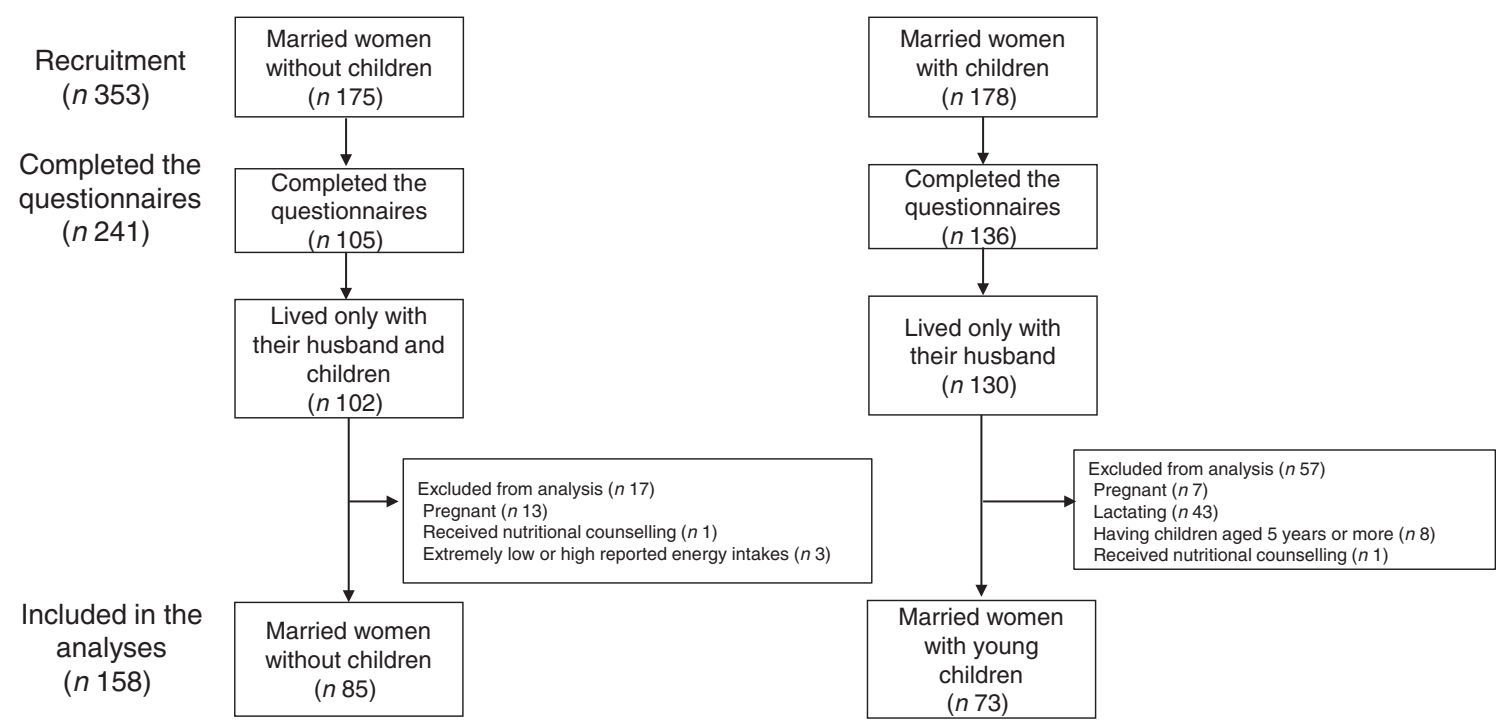

Fig. 1. Participation in the POTATO study comparing the dietary intake of Japanese married women with respect to the presence of young children in the home.

between the BDHQ and 16-d weighed dietary records was 0.54 (range 0.34-0.87), and the median Spearman's correlation coefficient of food intake was 0.44 (range 0.14 $0 \cdot 82)^{(31,32)}$. Although dietary supplement use was queried in the lifestyle questionnaire, intake via supplements was not included in the analysis because of the lack of a reliable composition table for dietary supplements in Japan.

\section{Assessment of lifestyle variables}

In the lifestyle questionnaire, the subjects reported their educational background (junior high school, high school, junior college or vocational technical school, or university); working status (full-time, part-time, other); household income (less than 2 million yen/year, 2 million to 6 million yen/year, 6 million to 10 million yen/year, more than 10 million yen/year); current smoking status (yes or no); and dietary supplement use (yes or no). Data regarding self-reported body height $(\mathrm{cm})$ and weight $(\mathrm{kg})$ were also obtained from the BDHQ. BMI was calculated as body weight $(\mathrm{kg})$ divided by the square of body height $\left(\mathrm{m}^{2}\right)$. On the basis of their reported home address, each participant was grouped into one of six residential blocks (Hokkaido and Tohoku, Kanto, Hokuriku and Tokai, Kinki, Chugoku and Shikoku, or Kyushu), and into three categories according to population size (city with a population $\geq 1$ million, city with a population $<1$ million, or town and village).

\section{Statistical analysis}

All statistical analyses were performed using SAS statistical software, version 9.4 (SAS Institute Inc.). All reported $P$ values were two-tailed, with $P<0.05$ considered statistically significant. Characteristics of the groups with and without children were compared using independent-samples $t$ tests for continuous variables and the $\chi^{2}$ test for categorical variables.

All the selected nutrient and food intake values were energy-adjusted using the density method (i.e. the percentage of energy for energy-providing nutrients and their amounts per $1000 \mathrm{kcal}(4184 \mathrm{~kJ})$ for food groups and other nutrients) to minimise the influence of dietary misreporting, which has caused ongoing controversy in studies that collect dietary information via self-reported instruments.

We examined the difference in the selected nutrient and food intake between subjects with young children and without children by using ANOVA. Additionally, multivariate adjusted mean, with standard error, for nutrient and food intake was calculated for subjects with young children or without children. Potential confounding factors considered in the analysis were those indicating differences between the two groups $(P<0 \cdot 1)$, namely, age (continuous variable), working status, annual household income, educational background and size of residential area, as detailed above. The categories of educational background and annual household income were regrouped due to the sample sizes of certain categories: $n 0$ for junior high school and $n 1$ for less than 2000000 yen/ year. The adjusted nutrient and food intake differences between the two groups were assessed by ANCOVA. To perform the ANCOVA tests, the number of participants required to detect a medium effect size $(f=0.25)$ with a significance level equal to $0 \cdot 05$, statistical power of 0.8 and five covariates was estimated to be 128 in total, according to the power analysis using $G^{*}$ Power $3^{(34)}$.

\section{Results}

Basic characteristics of subjects are shown in Table 1 . The mean age of the subjects was 32.5 (SD 4.5) years. The mean number of participants' children was 1.4 (SD 0.5). Compared with subjects with young children, those without children were younger, had a higher proportion of full-time workers, a lower proportion of annual household incomes less than 6 million yen per year, and a higher proportion of dwellers living in a city with a population $\geq 1$ million. No significant 
Table 1. Basic characteristics of 158 married women with or without young children at home (Mean values and standard deviations; numbers and percentages)

\begin{tabular}{|c|c|c|c|c|c|c|c|}
\hline & \multicolumn{2}{|c|}{ Total ( $n$ 158) } & \multicolumn{2}{|c|}{$\begin{array}{l}\text { With young } \\
\text { children }(n 73)\end{array}$} & \multicolumn{2}{|c|}{$\begin{array}{l}\text { Without children } \\
\quad(n \text { 85) }\end{array}$} & \multirow{2}{*}{$P^{*}$} \\
\hline & $n$ & $\%$ & $n$ & $\%$ & $n$ & $\%$ & \\
\hline Number of children & & & & & & & - \\
\hline Mean & & & 1.4 & & & & \\
\hline SD & & & 0.5 & & & & \\
\hline \multicolumn{8}{|l|}{ Number of children } \\
\hline 1 & & & 48 & $66 \cdot 7$ & & & - \\
\hline 2 & & & 23 & $30 \cdot 6$ & & & - \\
\hline More than 3 & & & 2 & $2 \cdot 8$ & & & - \\
\hline Age (years) & & & & & & & $<0.001$ \\
\hline Mean & & & & & & & \\
\hline SD & & & & & & & \\
\hline $\mathrm{BMI}\left(\mathrm{kg} / \mathrm{m}^{2}\right)$ & & & & & & & 0.135 \\
\hline Mean & & & & & & & \\
\hline SD & & & & & & & \\
\hline Energy intake $(\mathrm{kJ} / \mathrm{d})$ & & & & & & & 0.692 \\
\hline Mean & & & & & & & \\
\hline SD & & & & & & & \\
\hline Current smoking & & & & & & & 0.519 \\
\hline Yes & 6 & 3.8 & 2 & $2 \cdot 7$ & 4 & 4.7 & \\
\hline No & 152 & $96 \cdot 2$ & 71 & $97 \cdot 3$ & 81 & $95 \cdot 3$ & \\
\hline Dietary supplement user & & & & & & & 0.385 \\
\hline Yes & 42 & $26 \cdot 6$ & 17 & 23.3 & 25 & 29.4 & \\
\hline No & 116 & 73.4 & 56 & $76 \cdot 7$ & 60 & $70 \cdot 6$ & \\
\hline Educational background & & & & & & & 0.081 \\
\hline University or higher & 113 & 71.5 & 47 & 64.4 & 66 & $77 \cdot 7$ & \\
\hline Junior college or vocational technical school & 35 & $22 \cdot 2$ & 22 & $30 \cdot 1$ & 13 & $15 \cdot 3$ & \\
\hline High school & 10 & $6 \cdot 3$ & 4 & 5.5 & 6 & $7 \cdot 1$ & \\
\hline Working status & & & & & & & 0.042 \\
\hline Full-time & 73 & $46 \cdot 2$ & 26 & $35 \cdot 6$ & 47 & $55 \cdot 3$ & \\
\hline Part-time & 29 & $18 \cdot 4$ & 15 & $20 \cdot 6$ & 14 & $16 \cdot 5$ & \\
\hline Others & 56 & 35.4 & 32 & 43.8 & 24 & 28.2 & \\
\hline Annual household income & & & & & & & 0.039 \\
\hline Less than 6000000 yen & 70 & $44 \cdot 3$ & 40 & $54 \cdot 8$ & 30 & $35 \cdot 3$ & \\
\hline 6000000 yen to 10000000 yen & 65 & $41 \cdot 1$ & 23 & 31.5 & 42 & $49 \cdot 4$ & \\
\hline More than 10000000 yen & 23 & $14 \cdot 6$ & 10 & $13 \cdot 7$ & 13 & $15 \cdot 3$ & \\
\hline Survey year & & & & & & & 0.731 \\
\hline 2014 & 117 & $74 \cdot 1$ & 55 & $75 \cdot 3$ & 62 & 72.9 & \\
\hline 2015 & 41 & $26 \cdot 0$ & 18 & $24 \cdot 7$ & 23 & $27 \cdot 1$ & \\
\hline Residential block & & & & & & & 0.343 \\
\hline Hokkaido and Tohoku & 13 & 8.2 & 4 & $5 \cdot 5$ & 9 & $10 \cdot 6$ & \\
\hline Kanto & 84 & $53 \cdot 2$ & 45 & $61 \cdot 6$ & 39 & $45 \cdot 9$ & \\
\hline Hokuriku and Tokai & 15 & 9.5 & 6 & 8.2 & 9 & $10 \cdot 6$ & \\
\hline Kinki & 18 & 11.4 & 8 & 11.0 & 10 & 11.8 & \\
\hline Chugoku and Shikoku & 13 & $8 \cdot 2$ & 6 & $8 \cdot 2$ & 7 & $8 \cdot 2$ & \\
\hline Kyushu & 15 & 9.5 & 4 & 5.5 & 11 & 12.9 & \\
\hline Size of residential area & & & & & & & 0.027 \\
\hline City with a population $\geq 1$ million & 61 & 38.6 & 20 & $27 \cdot 4$ & 41 & 48.2 & \\
\hline City with a population $<1$ million & 84 & $53 \cdot 2$ & 46 & $63 \cdot 0$ & 38 & $44 \cdot 7$ & \\
\hline Town or village & 13 & $8 \cdot 2$ & 7 & $9 \cdot 6$ & 6 & $7 \cdot 1$ & \\
\hline
\end{tabular}

${ }^{\star} P$ values between married women with and without children. Means for continuous values were compared by using independent-samples $t$ tests, and proportions for categorical values were compared using the $\chi^{2}$ test.

differences were observed in BMI, energy intake, and the proportion of current smokers, supplement users, educational backgrounds, survey year, and residential blocks between women with and without children.

Table 2 shows the differences in nutrient intake between subjects with young children and without children. Women with young children had a significantly higher intake of $\mathrm{Na}$ than did women without children in the crude model. Even after adjusting for potential confounding factors, the intake of $\mathrm{Na}$ was significantly different between the two groups.
Additionally, in the multivariate models, women with young children also had a higher intake of proteins, carbohydrates, $\mathrm{Zn}$ and $\mathrm{Cu}$ than did those without children.

Intake of pulses and sugar was higher among women with young children than women without them, while intake of oil, alcoholic beverages, non-alcoholic beverages, and fruit and vegetable juices was higher among women without children than women with them (Table 3). In multivariate-adjusted models, similar results were observed with the addition of cereal intake. 
Table 2. Daily nutrient intake among 158 married women with and without young children at home (Mean values with their standard errors)

\begin{tabular}{|c|c|c|c|c|c|c|c|c|c|c|c|c|}
\hline \multirow[b]{3}{*}{ Nutrient } & \multicolumn{6}{|c|}{ Crude model } & \multicolumn{6}{|c|}{ Multivariate model† } \\
\hline & \multicolumn{2}{|c|}{$\begin{array}{l}\text { With young } \\
\text { children }(n 73)\end{array}$} & \multicolumn{2}{|c|}{$\begin{array}{c}\text { Without } \\
\text { children ( } n \text { 85) }\end{array}$} & \multirow[b]{2}{*}{ Difference } & \multirow[b]{2}{*}{$P \ddagger$} & \multicolumn{2}{|c|}{$\begin{array}{l}\text { With young } \\
\text { children ( } n \text { 73) }\end{array}$} & \multicolumn{2}{|c|}{$\begin{array}{c}\text { Without } \\
\text { children ( } n \text { 85) }\end{array}$} & \multirow[b]{2}{*}{ Difference } & \multirow[b]{2}{*}{$P \S$} \\
\hline & Mean & SE & Mean & SE & & & Mean & SE & Mean & SE & & \\
\hline Protein (\% energy) & $15 \cdot 6$ & 0.3 & 14.9 & 0.3 & 0.7 & 0.067 & $15 \cdot 8$ & 0.5 & $15 \cdot 0$ & 0.4 & 0.8 & $0.046^{*}$ \\
\hline Fat (\% energy) & $28 \cdot 0$ & 0.5 & 28.5 & 0.5 & 0.5 & 0.481 & $27 \cdot 3$ & 0.9 & $28 \cdot 1$ & 0.8 & 0.8 & 0.291 \\
\hline SFA (\% energy) & $7 \cdot 8$ & 0.2 & 7.9 & 0.2 & $0 \cdot 1$ & 0.724 & 7.5 & 0.3 & 7.7 & 0.3 & 0.2 & 0.663 \\
\hline Carbohydrate (\% energy) & 53.4 & 0.7 & 51.8 & 0.7 & 1.6 & 0.097 & 53.9 & 1.2 & $51 \cdot 2$ & $1 \cdot 1$ & $2 \cdot 7$ & $0.012^{*}$ \\
\hline Total dietary fibre (g/4184 kJ) & $7 \cdot 2$ & 0.2 & 6.8 & 0.2 & 0.4 & 0.194 & $7 \cdot 0$ & 0.4 & 6.5 & 0.3 & 0.5 & 0.145 \\
\hline Vitamin A ( $\mu \mathrm{g}$ RAE/4184 kJ)川 & 459 & 27 & 445 & 20 & 14 & 0.673 & 412 & 40 & 412 & 37 & 0 & 0.999 \\
\hline Vitamin $B_{1}(\mathrm{mg} / 4184 \mathrm{~kJ})$ & 0.45 & 0.01 & 0.44 & 0.01 & 0.01 & 0.454 & 0.44 & 0.02 & 0.42 & 0.01 & 0.02 & 0.303 \\
\hline Vitamin $B_{2}(\mathrm{mg} / 4184 \mathrm{~kJ})$ & 0.71 & 0.02 & 0.73 & 0.02 & 0.02 & 0.602 & 0.70 & 0.03 & 0.71 & 0.03 & 0.01 & 0.517 \\
\hline Niacin (mg NE/4184 kJ)ף & $9 \cdot 4$ & 0.3 & $9 \cdot 3$ & 0.3 & 0.1 & 0.792 & $9 \cdot 3$ & 0.5 & $9 \cdot 3$ & 0.5 & 0.0 & 0.945 \\
\hline Vitamin $B_{6}(\mathrm{mg} / 4184 \mathrm{~kJ})$ & 0.72 & 0.02 & 0.71 & 0.02 & 0.01 & 0.718 & 0.71 & 0.03 & 0.69 & 0.03 & 0.02 & 0.655 \\
\hline Vitamin $B_{12}(\mu \mathrm{g} / 4184 \mathrm{~kJ})$ & 5.01 & 0.26 & 4.40 & 0.27 & 0.61 & 0.109 & 5.54 & 0.46 & 4.85 & 0.42 & 0.69 & 0.093 \\
\hline Folate $(\mu \mathrm{g} / 4184 \mathrm{~kJ})$ & 192 & 8 & 197 & 7 & 5 & 0.609 & 188 & 14 & 192 & 13 & 4 & 0.729 \\
\hline Vitamin C (mg/4184 kJ) & 61 & 3 & 62 & 3 & 1 & 0.650 & 61 & 5 & 60 & 4 & 1 & 0.839 \\
\hline $\mathrm{Na}$ (salt-equivalent) $(\mathrm{g} / 4184 \mathrm{~kJ}) \dagger \dagger$ & $5 \cdot 8$ & 0.1 & $5 \cdot 3$ & 0.1 & 0.5 & $0.004^{*}$ & 6.4 & 0.2 & 5.8 & 0.2 & 0.6 & $0.001^{*}$ \\
\hline $\mathrm{K}(\mathrm{mg} / 4184 \mathrm{~kJ})$ & 1422 & 40 & 1408 & 37 & 14 & 0.801 & 1370 & 67 & 1350 & 63 & 20 & 0.739 \\
\hline $\mathrm{Ca}(\mathrm{mg} / 4184 \mathrm{~kJ})$ & 305 & 10 & 290 & 10 & 15 & 0.302 & 294 & 17 & 280 & 16 & 14 & 0.360 \\
\hline Mg (mg/4184 kJ) & 139 & 3 & 135 & 3 & 4 & 0.302 & 139 & 5 & 135 & 5 & 4 & 0.325 \\
\hline $\mathrm{Fe}(\mathrm{mg} / 4184 \mathrm{k})$ & 4.45 & 0.12 & 4.34 & 0.11 & 0.11 & 0.506 & 4.54 & 0.20 & 4.39 & $0 \cdot 19$ & 0.15 & 0.404 \\
\hline Zn (mg/4184 kJ) & 4.60 & 0.06 & 4.47 & 0.06 & 0.13 & 0.158 & 4.56 & 0.11 & 4.37 & $0 \cdot 10$ & 0.19 & $0.048^{*}$ \\
\hline $\mathrm{Cu}(\mathrm{mg} / 4184 \mathrm{~kJ})$ & 0.64 & 0.01 & 0.61 & 0.01 & 0.03 & 0.057 & 0.65 & 0.02 & 0.61 & 0.02 & 0.04 & $0.009^{*}$ \\
\hline
\end{tabular}

$\mathrm{NE}$, niacin equivalents; RAE, retinol activity equivalents.

${ }^{*} P<0.05$.

† The model included age (continuous variable), working status (full-time, part-time, or other), annual household income (less than 6000000 yen/year, 6000000 to 10000000 yen/year, or more than 10000000 yen/year), educational background (high school, junior college or vocational technical school, or university), and size of residential area (city with a population $\geq 1$ million, city with a population $<1$ million, or town/village)

$\ddagger P$ values between married women with and without children (ANOVA).

$\S P$ values between married women with and without children (ANCOVA).

II Sum of retinol, $\beta$-carotene/12, $\alpha$-carotene/24 and cryptoxanthin/24.

ๆ Sum of niacin and protein/6000.

†† $\mathrm{Na} \times 2.54$.

\section{Discussion}

To the best of our knowledge, the present study is the first to examine the difference in nutrient and food intake between Japanese married women with young children in the household and those without children. We found that there were several differences in nutrient and food intake profiles between the two groups of subjects. Parenthood is regarded as not only a period of transition in a person's life, but also a period of change in dietary habits. Dietary intake has been compared between parents and non-parents in overseas studies, many of which reported differences in fat intake. For example, in the USA, mothers with children aged 5 years old or younger had a greater intake of total energy and percentage of SFA than did women without children ${ }^{(12)}$. Another study also reported that the presence of children younger than 17 years old in the household was associated with greater intake of total fat and saturated fat ${ }^{(13)}$. Moreover, in a longitudinal study in the USA, adults who had new children in their homes had a greater intake of saturated fat than did nonparents ${ }^{(19)}$. Similarly, a Canadian study observed that the total intake of fat increased among new parents while it decreased among non-parents ${ }^{(21)}$. In contrast, our results showed that intake of other energy-providing nutrients, namely protein and carbohydrates, was higher among women with young children than among non-parents, while we observed no significant difference in the intake of fat and SFA between women with young children and those without them. These differences in nutrient intake reflected greater intake of cereals, pulses and sugars among subjects with young children in the present analysis. It has been reported that intake of fat and SFA is smaller in the Japanese population than in Western populations $^{(24)}$; moreover, this might have led to the differences between the present study's findings and those studies conducted in Western countries. Although we could not obtain children's dietary intake in cereals and pulses, a higher intake of these might reflect the children's dietary intake. Parents' food selections might be influenced by the presence of preschool children ${ }^{(35)}$. Asakura et al. ${ }^{(36)}$ reported that, according to dietary records of children aged 3-6 years, wellmilled rice, soya sauce, egg, carrot, onion, milk, potato, tofu and pork are frequently consumed foods, and these results are partially consistent with our findings. On the other hand, a difference in cereal intake was observed only in the multivariate-adjusted model, where age was significantly associated with lower cereal intake. This could be explained by the older age of women in the group with children than that of women in the group without children. This trend of higher grain intake among younger women is consistent with previous results in Japan ${ }^{(23)}$, although this might not be the influence of the presence of children in the households. To determine 
Table 3. Daily food intake among 158 married women with and without young children in the home (Mean values with their standard errors)

\begin{tabular}{|c|c|c|c|c|c|c|c|c|c|c|c|c|}
\hline \multirow[b]{3}{*}{ Food intake (g/4184 kJ) } & \multicolumn{6}{|c|}{ Crude model } & \multicolumn{6}{|c|}{ Multivariate model† } \\
\hline & \multicolumn{2}{|c|}{$\begin{array}{l}\text { With young } \\
\text { children } \\
(\text { ( } 73)\end{array}$} & \multicolumn{2}{|c|}{$\begin{array}{l}\text { Without } \\
\text { children } \\
\text { (n 85) }\end{array}$} & \multirow[b]{2}{*}{ Difference } & \multirow[b]{2}{*}{$P \ddagger$} & \multicolumn{2}{|c|}{$\begin{array}{l}\text { With young } \\
\text { children } \\
(n 73)\end{array}$} & \multicolumn{2}{|c|}{$\begin{array}{l}\text { Without } \\
\text { children } \\
\text { ( } n \text { 85) }\end{array}$} & \multirow[b]{2}{*}{ Difference } & \multirow[b]{2}{*}{$P \S$} \\
\hline & Mean & SE & Mean & SE & & & Mean & SE & Mean & SE & & \\
\hline Cereals & 219.4 & 6.7 & 206.9 & 6.5 & $12 \cdot 5$ & 0.186 & 222.5 & 11.6 & 201.6 & $10 \cdot 8$ & 20.9 & $0.046^{*}$ \\
\hline Rice & $156 \cdot 6$ & 7.0 & $151 \cdot 7$ & 7.0 & 4.9 & 0.618 & $152 \cdot 7$ & 11.9 & $137 \cdot 2$ & $11 \cdot 1$ & $15 \cdot 5$ & 0.150 \\
\hline Noodles & 39.5 & 3.3 & 34.8 & 2.6 & 4.7 & 0.261 & $50 \cdot 1$ & 4.9 & 44.0 & 4.6 & $6 \cdot 1$ & 0.170 \\
\hline Bread & 23.3 & 1.7 & $20 \cdot 4$ & 2.0 & $2 \cdot 9$ & 0.296 & $19 \cdot 8$ & $3 \cdot 3$ & $20 \cdot 4$ & $3 \cdot 1$ & 0.6 & 0.844 \\
\hline Pulses & $126 \cdot 8$ & 7.3 & $99 \cdot 2$ & 5.1 & $27 \cdot 6$ & $0.002^{*}$ & $145 \cdot 7$ & $10 \cdot 7$ & 111.3 & $10 \cdot 0$ & 34.4 & $0.001^{*}$ \\
\hline Potatoes & $25 \cdot 6$ & 1.7 & 23.0 & $2 \cdot 2$ & $2 \cdot 6$ & 0.349 & $25 \cdot 3$ & 3.4 & $20 \cdot 7$ & $3 \cdot 2$ & 4.6 & 0.136 \\
\hline Sugar and confectioneries & $44 \cdot 2$ & 3.7 & $45 \cdot 6$ & 2.6 & 1.4 & 0.739 & $49 \cdot 4$ & 5.4 & $50 \cdot 1$ & $5 \cdot 1$ & 0.7 & 0.885 \\
\hline Sugar & 3.0 & 0.2 & $2 \cdot 3$ & 0.2 & 0.7 & $0.024^{*}$ & 3.0 & 0.4 & $2 \cdot 3$ & 0.4 & 0.7 & $0.042^{*}$ \\
\hline Confectioneries & $41 \cdot 2$ & 3.7 & 43.4 & 2.6 & $2 \cdot 2$ & 0.623 & 46.4 & 5.5 & $47 \cdot 8$ & $5 \cdot 1$ & 1.4 & 0.774 \\
\hline Oil & 9.5 & 0.4 & $10 \cdot 8$ & 0.4 & 1.3 & $0.013^{*}$ & 8.7 & 0.7 & $10 \cdot 4$ & 0.6 & 1.7 & $0.005^{*}$ \\
\hline Fruits & 33.7 & 3.0 & $29 \cdot 2$ & 2.5 & 4.5 & 0.245 & $32 \cdot 0$ & 4.6 & $27 \cdot 1$ & 4.3 & 4.9 & 0.240 \\
\hline Total vegetables & 166.9 & $10 \cdot 1$ & 163.9 & 8.3 & 3.0 & 0.819 & 157.9 & $16 \cdot 2$ & 152.4 & $15 \cdot 0$ & 5.5 & 0.707 \\
\hline Green and yellow vegetables & 64.7 & 4.7 & 61.5 & 4.2 & $3 \cdot 2$ & 0.612 & $56 \cdot 8$ & 7.7 & 54.0 & $7 \cdot 2$ & $2 \cdot 8$ & 0.683 \\
\hline Other vegetables & $81 \cdot 3$ & 5.6 & 81.9 & 4.3 & 0.6 & 0.933 & 79.2 & 8.6 & 77.5 & 8.0 & 1.7 & 0.835 \\
\hline Pickled vegetables & 5.5 & 0.8 & 4.7 & 0.7 & 0.8 & 0.435 & $7 \cdot 8$ & 1.3 & 6.4 & 1.2 & 1.4 & 0.234 \\
\hline Mushrooms & 8.4 & 0.6 & $9 \cdot 0$ & 0.7 & 0.6 & 0.499 & 7.5 & $1 \cdot 1$ & $8 \cdot 1$ & $1 \cdot 1$ & 0.6 & 0.598 \\
\hline Seaweeds & $7 \cdot 0$ & 0.7 & $6 \cdot 8$ & 0.7 & 0.2 & 0.854 & $6 \cdot 6$ & $1 \cdot 1$ & 6.5 & $1 \cdot 1$ & $0 \cdot 1$ & 0.910 \\
\hline Alcoholic beverages & 37.4 & $10 \cdot 4$ & 73.6 & 13.1 & $36 \cdot 2$ & $0.036^{*}$ & 34.6 & 19.9 & $89 \cdot 6$ & 18.5 & 55.0 & $0.003^{*}$ \\
\hline Non-alcoholic beverages & 254.8 & $19 \cdot 8$ & 319.0 & 21.6 & $64 \cdot 2$ & $0.032^{*}$ & $280 \cdot 4$ & $37 \cdot 0$ & 347.5 & 34.4 & $67 \cdot 1$ & $0.045^{*}$ \\
\hline Fruit and vegetable juice & $17 \cdot 1$ & 3.0 & $31 \cdot 3$ & $5 \cdot 0$ & $14 \cdot 2$ & $0.020^{*}$ & 21.8 & 7.5 & 36.5 & 6.9 & $14 \cdot 7$ & $0.030^{\star}$ \\
\hline Green, black and oolong tea & 133.2 & $19 \cdot 1$ & 179.9 & $16 \cdot 5$ & $46 \cdot 7$ & 0.064 & 165.4 & 31.4 & 204.5 & $29 \cdot 3$ & $39 \cdot 1$ & $0 \cdot 168$ \\
\hline Coffee & 81.8 & $10 \cdot 3$ & 82.9 & $10 \cdot 9$ & $1 \cdot 1$ & 0.941 & $59 \cdot 6$ & $18 \cdot 3$ & 73.6 & $17 \cdot 1$ & $14 \cdot 0$ & 0.397 \\
\hline Soft drinks & $22 \cdot 7$ & 3.5 & $24 \cdot 8$ & 4.6 & $2 \cdot 1$ & 0.721 & 33.6 & $7 \cdot 3$ & 33.0 & $6 \cdot 8$ & 0.6 & 0.924 \\
\hline Fish and shellfish & $40 \cdot 9$ & $2 \cdot 7$ & $36 \cdot 1$ & 3.0 & $4 \cdot 8$ & 0.246 & $48 \cdot 0$ & 4.9 & $40 \cdot 6$ & 4.6 & 7.4 & 0.099 \\
\hline Meats & 43.9 & 1.9 & $45 \cdot 7$ & 1.6 & 1.8 & 0.457 & $40 \cdot 0$ & 3.0 & $42 \cdot 0$ & $2 \cdot 8$ & $2 \cdot 0$ & 0.465 \\
\hline Eggs & $20 \cdot 8$ & 1.4 & $21 \cdot 1$ & 1.4 & 0.3 & 0.898 & 21.9 & 2.4 & $22 \cdot 7$ & $2 \cdot 2$ & 0.8 & 0.705 \\
\hline Dairy products & $64 \cdot 1$ & 6.4 & 63.5 & 5.2 & 0.6 & 0.940 & $42 \cdot 2$ & $10 \cdot 0$ & $46 \cdot 2$ & $9 \cdot 3$ & 4.0 & 0.662 \\
\hline
\end{tabular}

${ }^{*} P<0.05$.

† The model included age (continuous variable), working status (full-time, part-time, or other), annual household income (less than 6000000 yen/year, 6000000 to 10000000 yen/year, or more than 10000000 yen/year), educational background (high school, junior college or vocational technical school, or university), and size of residential area (city with a population $\geq 1$ million, city with a population $<1$ million, or town/village).

$\ddagger P$ values between married women with and without children (ANOVA).

$\S P$ values between married women with and without children (ANCOVA).

whether children's dietary intake or preferences influence the dietary habit of their parents in the Japanese population, further studies are needed.

In the present study, mothers had higher intakes of $\mathrm{Na}, \mathrm{Zn}$ and $\mathrm{Cu}$ than did non-parents. One Japanese study reported that white rice was the largest contributor to the intake of $\mathrm{Zn}$ and $\mathrm{Cu}$, accounting for approximately $20 \%$ of $\operatorname{each}^{(37)}$. This study also showed that pulses and nuts contributed to the intake of these nutrients, which might explain why our subjects with young children had higher intakes of $\mathrm{Zn}$ and $\mathrm{Cu}$ than did the non-parents. The estimated difference in $\mathrm{Na}$ intake between the two groups could be as much as $1 \mathrm{~g} / \mathrm{d}$. One study reported that more than $60 \%$ of Japanese women's $\mathrm{Na}$ intake comes from seasonings such as soya sauce and salt ${ }^{(38)}$. However, we could not compare the intake of seasonings, because validity of the intake of these food items has not been examined in the BDHQ; thus the amounts of seasonings consumed could have been different between mothers and non-mothers. Although we could not refer to the effects of transition to parenthood in this cross-sectional study, mothers may need to be more conscious of their $\mathrm{Na}$ intake than they were when they did not have children. Meanwhile, in
Eastern Asia, particularly Japan, $\mathrm{Na}$ intake is greater than that in other countries ${ }^{(39)}$, which is a major health problem ${ }^{(40)}$. Our findings, therefore, may illustrate the need for implementing an effective strategy for reducing $\mathrm{Na}$ intake in the target population. Furthermore, children's dietary habits could be influenced by the dietary habits of their parents ${ }^{(6)}$. Therefore, health-promotion programmes, including nutrition counselling, may need to draw mothers' attention to $\mathrm{Na}$ intake, not only for themselves, but also for their children, who could carry these dietary habits into the future.

Our subjects with young children had a lower intake of alcoholic beverages. This result is consistent with a US study showing that motherhood is associated with marked reductions in alcohol consumption ${ }^{(41)}$. Alcohol reduction during pregnancy and lactation could continue after these periods. Since alcohol intake, in turn, affects intake of foods and nutrients, the differences in dietary intake observed in the present study could have been influenced by the intake of alcoholic beverages. For example, one study showed that moderate or heavy drinkers had a lower intake of carbohydrates than did non-drinkers among Finnish women ${ }^{(42)}$. Moreover, one study in the USA comparing dietary intake on a drinking 
day with that of a non-drinking day observed lower intakes of discretionary oil and solid fat on a non-drinking day among women $^{(43)}$, which is partially consistent with our findings. Dietary intake of married women could be affected not only by the presence of young children at home, but also by behavioural changes during pregnancy and lactation. Interestingly, we found that mothers also had a lower intake of nonalcoholic beverages, particularly fruit and vegetable juices, than did non-mothers. Another US study showed that mothers with young children had a greater intake of sugar-sweetened beverages than did women without children, which differs from the results of our findings ${ }^{(12)}$. Among Japanese young women, it has been reported that a higher intake of soft drinks was associated with lower intakes of protein, dietary fibre, vitamins and minerals, even though their intake of soft drinks was lower than that of the US population $^{(44)}$. With a few exceptions, this result is consistent with our results. Additionally, the present study showed that there was no difference in reported energy intake between the two groups. A Canadian study on beverage consumption patterns reported that a smaller amount of beverage intake was associated with lower energy intake ${ }^{(45)}$. It could be said, therefore, that Japanese mothers derive more energy or nutrients from foods, than from beverages. Further studies are needed to examine beverage consumption patterns and their effect on dietary intake in the Japanese population, in addition to the influence of the presence of young children in a home on beverage consumption. Nevertheless, our findings indicated that beverage intake habits could change during the transition to motherhood.

Our study has several limitations. First, the subjects of this study were recruited based on a snowball-recruitment strategy and were, therefore, not a random sample of Japanese adult women. The advertisement was distributed mainly via graduates of several universities; thus, all the subjects might have had relatively high social and economic status. Compared with dietary intake data of women aged 30-39 years in the National Health and Nutrition Survey in Japan, 2016 ${ }^{(23)}$, which represented the general Japanese population, the fat and carbohydrate energy ratio was slightly lower in the current participants. Due to our recruitment strategy, women who were interested in nutrition were more likely to participate, thus selection bias could not be ruled out. This might explain the small differences between the groups. Moreover, data were only collected among women who lived with their husbands, either with or without children younger than 5 years of age. This strategy was employed to examine the effect made by the presence of children; however, results cannot be extrapolated beyond that. Second, the period of recruitment and the consequent data collection differed based on survey years (2014: June to December; 2015: July to August); thus, the difference in dietary intake by seasons may need to be considered. Because the number of subjects participating in 2014 and 2015 did not differ between the groups, we did not consider this factor in the multivariate analyses. Although the number of subjects was not sufficiently large enough to make a comparison by survey seasons, the results did not differ when we adjusted for the survey years in addition to the multivariate adjustment models (data not shown). Additionally, validation of the BDHQ used 4-d dietary records conducted in each of the four seasons over the period of 1 year as the reference method for minimising the effect of seasonal dietary intake variations ${ }^{(32)}$. Furthermore, the aforementioned study examined the validity by using not only a single season's results of the questionnaire but also the mean values of four seasons' results; thus, we considered that the season variation could be minimised. Third, we were unable to obtain nutrient intake information regarding dietary supplementation. Approximately one-quarter of each group used dietary supplements; thus, the intake from dietary supplements could have affected the results to some extent. Moreover, supplement use could not be evaluated because of the lack of a reliable composition table of dietary supplements in Japan. However, the proportion of dietary supplement users did not differ between the two groups, which may support the robustness of the present findings. Fourth, there could be other confounding factors in addition to those we examined. For example, among women having young children, some subjects may have been on childcare leave from their full- or part-time jobs. In this case, the working status was considered as 'other'; therefore, the effect on the results from such factors could not be ruled out. Finally, this is a cross-sectional study, and therefore causal relationships were not clarified. It is possible that the women with children already had concrete dietary behaviours before they transitioned to motherhood. Without a longitudinal study, therefore, we cannot say definitively that the presence of a child is responsible for a positive/negative change in dietary habits.

\section{Conclusions}

This cross-sectional study showed that there were several differences in the intake of nutrients and foods between married Japanese women with young children and those without children. Our findings suggest that the presence of young children might influence a mother's intake of macronutrients and some minerals, as well as beverage intake habits. Moreover, our findings indicate that mothers especially need to attend to their $\mathrm{Na}$ intake. Thus, health-promotion programmes or nutrition counselling might need to pay greater attention to this special period in a mother's life in which great changes can occur in her dietary habits. Further studies, including longitudinal studies, are needed to clarify the association between the presence of children in households and adults' dietary habits.

\section{Acknowledgements}

We thank the members of the Study Group of Nutritional Epidemiology in Tokyo who served as collaborators, and Drs Satoshi Sasaki and Satomi Kobayashi (University of Tokyo), Dr Kaoruko Iida (Ochanomizu University), Dr Shinji Ikemoto (Seitoku University) and Dr Hidemi Takimoto (National Institute of Biomedical Innovation, Health and Nutrition) for their supportive comments on our work. 
This work was supported by the Institute for Food and Health Science, Yazuya Co., Ltd (subsidy of 2013).

Author contributions were as follows: all authors contributed to the concept and design of the survey and data collection. M. M., A. H. and M. S. contributed to data management. A. S. and A. H. conducted the statistical analysis. A. S. drafted the paper. M. M, A. H., M. S. and N. O. provided input for the final draft of the manuscript. All authors read and approved the final manuscript.

There were no conflicts of interest.

\section{References}

1. Skinner JD, Carruth BR, Bounds W, et al. (2002) Children's food preferences: a longitudinal analysis. J Am Diet Assoc 102, 1638 1647.

2. Birch LL, Fisher JO, Troiano R, et al. (1998) Development of eating behaviors among children and adolescents. Pediatrics 101, 539-549.

3. Mikkilä V, Räsänen L, Raitakari O, et al. (2004) Longitudinal changes in diet from childhood into adulthood with respect to risk of cardiovascular diseases: the Cardiovascular Risk in Young Finns study. Eur J Clin Nutr 58, 1038-1045.

4. Kaikkonen JE, Mikkilä V \& Raitakari OT (2014) Role of childhood food patterns on adult cardiovascular disease risk. Curr Atheroscler Rep 16, 443.

5. Wang Y, Beydoun MA, Li J, et al. (2011) Do children and their parents eat a similar diet? Resemblance in child and parental dietary intake: systematic review and meta-analysis. J Epidemiol Community Health 65, 177-189.

6. Larsen JK, Hermans RCJ, Sleddens EFC, et al. (2015) How parental dietary behavior and food parenting practices affect children's dietary behavior. Interacting sources of influence? Appetite 89, 246-257.

7. Robson SM, Couch SC, Peugh JL, et al. (2016) Parent diet quality and energy intake are related to child diet quality and energy intake. J Acad Nutr Diet 116, 984-990.

8. Gunderson EP \& Abrams B (1999) Epidemiology of gestational weight gain and body weight changes after pregnancy. Epidemiol Rev 21, 261-275.

9. Laroche HH, Wallace RB, Snetselaar L, et al. (2013) Weight gain among men and women who have a child enter their home. I Acad Nutr Diet 113, 1504-1510.

10. Hull EE, Rofey DL, Robertson RJ, et al. (2010) Influence of marriage and parenthood on physical activity: a 2-year prospective analysis. I Phys Act Heal 7, 577-583.

11. Bellows-Riecken KH \& Rhodes RE (2008) A birth of inactivity? A review of physical activity and parenthood. Prev Med 46, 99-110.

12. Berge JM, Larson N, Bauer KW, et al. (2011) Are parents of young children practicing healthy nutrition and physical activity behaviors? Pediatrics 127, 881-887.

13. Laroche HH, Hofer TP \& Davis MM (2007) Adult fat intake associated with the presence of children in households: findings from NHANES III. J Am Board Fam Med 20, 9-15.

14. Pollard J, Greenwood D, Kirk S, et al. (2001) Lifestyle factors affecting fruit and vegetable consumption in the UK Women's Cohort Study. Appetite 37, 71-79.

15. Roos E, Lahelma E, Virtanen M, et al. (1998) Gender, socioeconomic status and family status as determinants of food behaviour. Soc Sci Med 46, 1519-1529.

16. Devine CM, Wolfe WS, Frongillo EA, et al. (1999) Life-course events and experiences: association with fruit and vegetable consumption in 3 ethnic groups. J Am Diet Assoc 99, 309-314.

17. Smith KJ, McNaughton SA, Gall SL, et al. (2017) Associations between partnering and parenting transitions and dietary habits in young adults. J Acad Nutr Diet 117, 1210-1221.
18. Hartmann C, Dohle S \& Siegrist M (2014) Time for change? Food choices in the transition to cohabitation and parenthood. Public Health Nutr 17, 2730-2739.

19. Laroche HH, Wallace RB, Snetselaar L, et al. (2012) Changes in diet behavior when adults become parents. J Acad Nutr Diet 112, 832839.

20. Olson CM (2005) Tracking of food choices across the transition to motherhood. J Nutr Educ Behav 37, 129-136.

21. Nasuti G, Blanchard C, Naylor PJ, et al. (2014) Comparison of the dietary intakes of new parents, second-time parents, and nonparents: a longitudinal cohort study. J Acad Nutr Diet 114, 450-456.

22. Elstgeest LEM, Mishra GD \& Dobson AJ (2012) Transitions in living arrangements are associated with changes in dietary patterns in young women. J Nutr 142, 1561-1567.

23. Ministry of Health, Labour and Welfare (2017) The National Health Nutrition Survey in Japan, 2016. http://www.mhlw.go.jp/bunya/ kenkou/eivou/h28-houkoku.html (accessed February 2018).

24. Micha R, Khatibzadeh S, Shi P, et al. (2014) Global, regional, and national consumption levels of dietary fats and oils in 1990 and 2010: a systematic analysis including 266 country-specific nutrition surveys. BMJ 348, g2272.

25. Park HS, Yim KS \& Cho SI (2004) Gender differences in familial aggregation of obesity-related phenotypes and dietary intake patterns in Korean families. Ann Epidemiol 14, 486-491.

26. Rhodes K, Chan F, Prichard I, et al. (2016) Intergenerational transmission of dietary behaviours: a qualitative study of Anglo-Australian, Chinese-Australian and Italian-Australian three-generation families. Appetite 103, 309-317.

27. Shrivastava A, Murrin C, Sweeney MR, et al. (2013) Familial intergenerational and maternal aggregation patterns in nutrient intakes in the lifeways cross-generation cohort study. Public Health Nutr 16, 1476-1486.

28. Collins LJ, Lacy KE, Campbell KJ, et al. (2016) The predictors of diet quality among Australian children aged 3.5 years. J Acad Nutr Diet 116, 1114-1126.e2.

29. Ministry of Health, Labour and Welfare (2017) Vital Statistics in Japan - Trends up to 2015. Tokyo: Director-General for Statistics and Information Policy, Ministry of Health, Labour and Welfare.

30. Ministry of Health, Labour and Welfare (2014) Dietary Reference Intakes for Japanese, 2015. Tokyo: Daiichi Shuppan Publishing Co., Ltd.

31. Kobayashi S, Honda S, Murakami K, et al. (2012) Both comprehensive and brief self-administered diet history questionnaires satisfactorily rank nutrient intakes in Japanese adults. J Epidemiol 22, 151159.

32. Kobayashi S, Murakami K, Sasaki S, et al. (2011) Comparison of relative validity of food group intakes estimated by comprehensive and brief-type self-administered diet history questionnaires against $16 \mathrm{~d}$ dietary records in Japanese adults. Public Health Nutr 14, $1200-1211$.

33. The Council for Science and Technology, Ministry of Education, Culture, Sports and Technology (2010) Standard Tables of Food Composition in Japan - 2010. Tokyo: Official Gazette Co-operation.

34. Faul F, Erdfelder E, Lang A-G, et al. (2007) G*power: a flexible statistical power analysis program for the social, behavioral, and biomedical sciences. Behav Res Methods 39, 175-191.

35. O’Dougherty M, Story M \& Stang J (2006) Observations of parentchild co-shoppers in supermarkets: children's involvement in food selections, parental yielding, and refusal strategies. J Nutr Educ Behav 38, 183-188.

36. Asakura K, Haga M, Adachi M, et al. (2014) Estimation of food portion sizes frequently consumed by children 3-6 years old in Japan. J Nutr Sci Vitaminol 60, 387-396.

37. Yamada M, Asakura K, Sasaki S, et al. (2014) Estimation of intakes of copper, zinc, and manganese in Japanese adults using 16-day semi-weighed diet records. Asia Pac J Clin Nutr 23, 465-472.

38. Asakura K, Uechi K, Masayasu S, et al. (2016) Sodium sources in the Japanese diet: difference between generations and sexes. Public Health Nutr 19, 2011-2023. 
39. Asakura K, Uechi K, Sasaki Y, et al. (2014) Estimation of sodium and potassium intakes assessed by two $24 \mathrm{~h}$ urine collections in healthy Japanese adults: a nationwide study. Br J Nutr 112, 1195-1205.

40. Forouzanfar MH, Alexander L, Anderson HR, et al. (2015) Global, regional, and national comparative risk assessment of 79 behavioural, environmental and occupational, and metabolic risks or clusters of risks in 188 countries, 1990-2013: a systematic analysis for the Global Burden of Disease Study 2013. Lancet 386, 2287-2323.

41. Matusiewicz AK, Ilgen MA \& Bohnert KM (2016) Changes in alcohol use following the transition to motherhood: findings from the National Epidemiologic Survey on Alcohol and Related Conditions. Drug Alcohol Depend 168, 204-210.
42. Fawehinmi TO, Ilomäki J, Voutilainen S, et al. (2012) Alcohol consumption and dietary patterns: the FinDrink Study. PLOS ONE 7, e38607.

43. Breslow RA, Chen CM, Graubard BI, et al. (2013) Diets of drinkers on drinking and nondrinking days: NHANES 2003-2008. Am J Clin Nutr 97, 1068-1075.

44. Yamada M, Murakami K, Sasaki S, et al. (2008) Soft drink intake is associated with diet quality even among young Japanese women with low soft drink intake. J Am Diet Assoc 108, 1997-2004.

45. Nikpartow N, Danyliw AD, Whiting SJ, et al. (2012) Beverage consumption patterns of Canadian adults aged 19 to 65 years. Public Health Nutr 15, 2175-2184. 